[Chem. Pharm. Bull.

35( 3$) 1030-1035(1987)$

\title{
Synthesis of 2-Substituted 5-(1-Oxido-4-pyridyl)- and 5-(1-Oxido- 2-pyridyl)-1,3,4-thiadiazole Derivatives by Substitution of 2-Methylsulfonyl Group with Various Nucleophiles
}

\author{
Kouhei Toyooka, Yasushi Kawashima, and Seiju Kubota* \\ Faculty of Pharmaceutical Sciences, University of Tokushima, \\ Shomachi. Tokushima 770, Japan
}

(Received August 28, 1986)

\begin{abstract}
The synthesis of 2-substituted 5-(1-oxido-4-pyridyl)-(4a-10a) and 5-(1-oxido-2-pyridyl)-1,3,4thiadiazole derivatives $(\mathbf{4 b}-\mathbf{1 0 b})$ by substitution reaction of 5-(1-oxido-4-pyridyl)- (3a) and 5-(1oxido-2-pyridyl)-2-methylsulfonyl-1,3,4-thiadiazole (3b) is described. 5-(1-Oxido-4-pyridyl)- (9a) and 5-(1-oxido-2-pyridyl)-1,3,4-thiadiazole (9b) could be reduced with sodium dithionite to 2-(4pyridyl)- (11c) and 2-(2-pyridyl)-1,3,4-thiadiazole (11d).
\end{abstract}

Keywords -2,3-dihydro-1,3,4-thiadiazole; oxidation; methylsulfonyl-1,3,4-thiadiazole; nucleophilic substitution; nucleophile; substituted 1,3,4-thiadiazole; hydrolysis; sodium borohydride; (1-oxidopyridyl)-1,3,4-thiadiazole; sodium dithionite

The most common procedure for the synthesis of 2,5-disubstituted 1,3,4-thiadiazoles is based on cyclization of acylated thiosemicarbazides or compounds with similar structures. ${ }^{1}$ Nucleophilic substitution reaction of 1,3,4-thiadiazole derivatives with strong electronwithdrawing substituents in the 2-position is a valuable procedure for preparing 2,5disubstituted 1,3,4-thiadiazole derivatives which are not readily obtainable by the common procedures.

A substituent such as a halogen atom ${ }^{2)}$ or nitro group ${ }^{3)}$ in 1,3,4-thiadiazole derivatives can be readily displaced by nucleophiles, due to the low electron density at the carbon atoms in the 1,3,4-thiadiazole ring. It has also been reported that methylsulfonyl groups at carbons with low electron density in heterocyclic compounds can be displaced with nucleophiles. ${ }^{4)} 2$ Hydrazino-5-phenyl-1,3,4-thiadiazole has been prepared by hydrazinolysis of 2-methylsulfonyl-5-phenyl-1,3,4-thiadiazole. ${ }^{5}$

Previously, we have reported that acetylation of both pyridine-carbaldehyde methylthio(thiocarbonyl)hydrazones (1a,1b) with acetic anhydride gave the 2,3-dihydro-1,3,4thiadiazoles $(\mathbf{2} \mathbf{a}, \mathbf{2} \mathbf{b})$ and oxidation of $\mathbf{2 a}, \mathbf{2} \mathbf{b}$ with an excees of $30 \%$ hydrogen peroxide in acetic acid gave 2-methylsulfonyl-5-(1-oxido-pyridyl)-1,3,4-thiadiazoles (3a, $\mathbf{3 b}$ ) in good yields $^{6)}$ (Chart 1).

We here report on the substitution reaction of the 2-methylsulfonyl-1,3,4-thiadiazoles<smiles>[R]/C=N\NC(=S)SC</smiles>

$$
\begin{array}{ll}
\text { 1a: } & R=4 \text {-pyridyl } \\
\text { 1b: } & R=2 \text {-pyridyl }
\end{array}
$$<smiles>[R]C1SC([Hg])=NN1C(C)=O</smiles>

2a: $\quad \mathrm{R}=4$-pyridyl

2b : $\quad R=2$-pyridyl

Chart 1<smiles>[R]c1nnc(S(=O)(=O)OC)s1</smiles>

3a: $\quad \mathrm{R}=1$-oxido-4-pyridyl

3b : $\quad \mathrm{R}=1$-oxido-2-pyridyl 
<smiles>[R]c1nnc(OCC)s1</smiles>

$4 a, 4 b$<smiles>[R]c1n[nH]c(=O)s1</smiles>

$10 \mathrm{a}, 10 \mathrm{~b}$

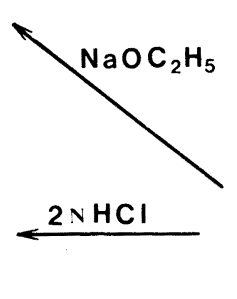

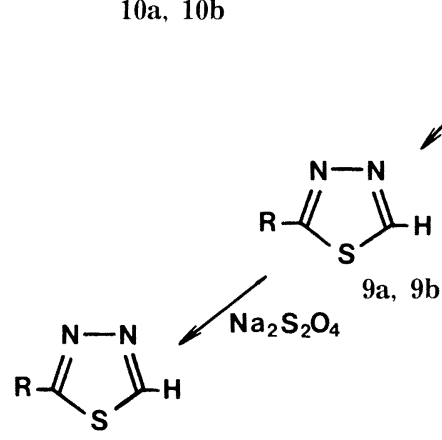

$11 \mathrm{c}, 11 \mathrm{~d}$<smiles>[R]c1nnc(Sc2ccccc2)s1</smiles>

$5 a, 5 b$<smiles>[R]c1nnc(Nc2ccccc2)s1</smiles>

$6 a, 6 b$

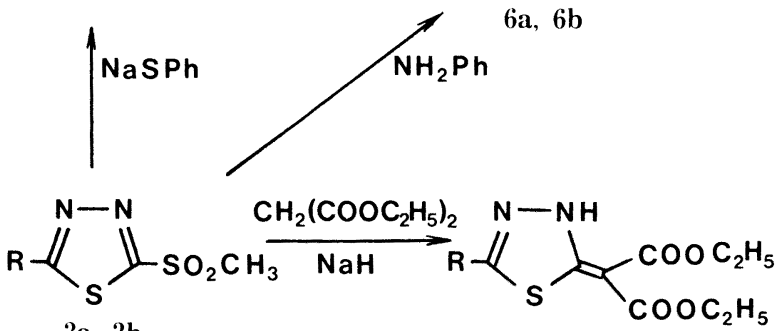

$3 \mathbf{a}, 3 \mathbf{b}$

$7 \mathbf{a}, 7 \mathbf{b}$

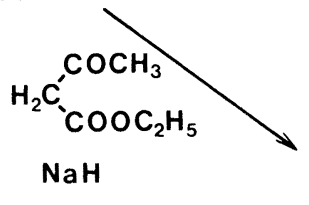<smiles>[R]OC(=O)C(C(=O)OCC)=C1NN=C([R])S1</smiles>

$8 \mathbf{a}, 8 \mathbf{b}$

a : 1-oxido-4-pyridyl
b :1-oxido-2-pyridyl
c $: 4$-pyridyl
d : 2-pyridyl

Chart 2

$(\mathbf{3 a}, \mathbf{3 b})$ with various nucleophiles. Treatment of $\mathbf{3 a}$ with sodium ethoxide in EtOH or with thiophenol in the presence of sodium hydride at room temperature gave 2-ethoxy- (4a) or 2phenylthio-5-(1-oxido-4-pyridyl)-1,3,4-thiadiazole (5a) in $77 \%$ or $78 \%$ yield, respectively. Reaction of 3a with aniline at elevated temperature gave 2-anilino-5-(1-oxido-4-pyridyl)1,3,4-thiadiazole (6a). Reaction of 3a with diethyl malonate or ethyl acetoacetate in the presence of sodium hydride afforded diethyl 5-(1-oxido-4-pyridyl)-2,3-dihydro-1,3,4thiadiazol-2-ylidenemalonate (7a) or ethyl 1-(5-(1-oxido-4-pyridyl)-2,3-dihydro-1,3,4thiadiazol-2-ylidene)-1-acetylacetate (8a) in $83 \%$ or $81 \%$ yield, respectively. The infrared (IR) spectra of compounds $7 \mathbf{a}$ and $8 \mathbf{a}$ showed $\mathrm{NH}$ absorptions at 3210 and $3230 \mathrm{~cm}^{-1}$, respectively. The proton nuclear magnetic resonance $\left({ }^{1} \mathrm{H}-\mathrm{NMR}\right)$ spectra of compounds $7 \mathbf{a}\left(\delta_{\mathrm{H}} 13.54\right)$ and $8 \mathbf{a}\left(\delta_{\mathbf{H}} 13.60\right)$ also indicate the presence of $\mathrm{NH}$ protons. These results show that 7a and $8 \mathbf{a}$ exist as the 2,3-dihydro-1,3,4-thiadiazole tautomers. Reaction of $\mathbf{3 a}$ with $\mathrm{NaBH}_{4}$ at room temperature gave 2-(1-oxido-4-pyridyl)-1,3,4-thiadiazole (9a) by substitution of the 2methylsulfonyl group with a hydride anion. Hydrolysis of 3a with $2 \mathrm{~N} \mathrm{HCl}$ under reflux gave 5-(1-oxido-4-pyridyl)-2,3-dihydro-1,3,4-thiadiazol-2-one (10a). The structures of compounds 4a-10a were supported by the analytical and spectral data (Table I).

Similar treatment of $\mathbf{3 b}$ with the nucleophiles described above also gave 2-substituted 5-(1oxido-2-pyridyl)-1,3,4-thiadiazoles $(\mathbf{4 b}-\mathbf{1 0 b})$. The structures of compounds $\mathbf{4 b}-\mathbf{1 0 b}$ were also supported by the analytical and spectral data (Table II).

It has been reported that pteridine $\mathrm{N}$-oxides could be easily reduced to pteridine by treatment with sodium dithionite $\left(\mathrm{Na}_{2} \mathrm{~S}_{2} \mathrm{O}_{4}\right) \cdot{ }^{7)}$ In fact, reduction of 9 a with 8 eq of $\mathrm{Na}_{2} \mathrm{~S}_{2} \mathrm{O}_{4}$ in $50 \%$ aqueous EtOH under reflux for $15 \mathrm{~min}$ gave 2-(4-pyridyl)-1,3,4-thiadiazole (11c) in $94 \%$ yield, while treatment of $\mathbf{9 b}$ with 30 eq of $\mathrm{Na}_{2} \mathrm{~S}_{2} \mathrm{O}_{4}$ in $50 \%$ aqueous $\mathrm{EtOH}$ under reflux for $1 \mathrm{~h}$ gave 2-(2-pyridyl)-1,3,4-thiadiazole (11d) ${ }^{8)}$ in only $56 \%$ yield. 


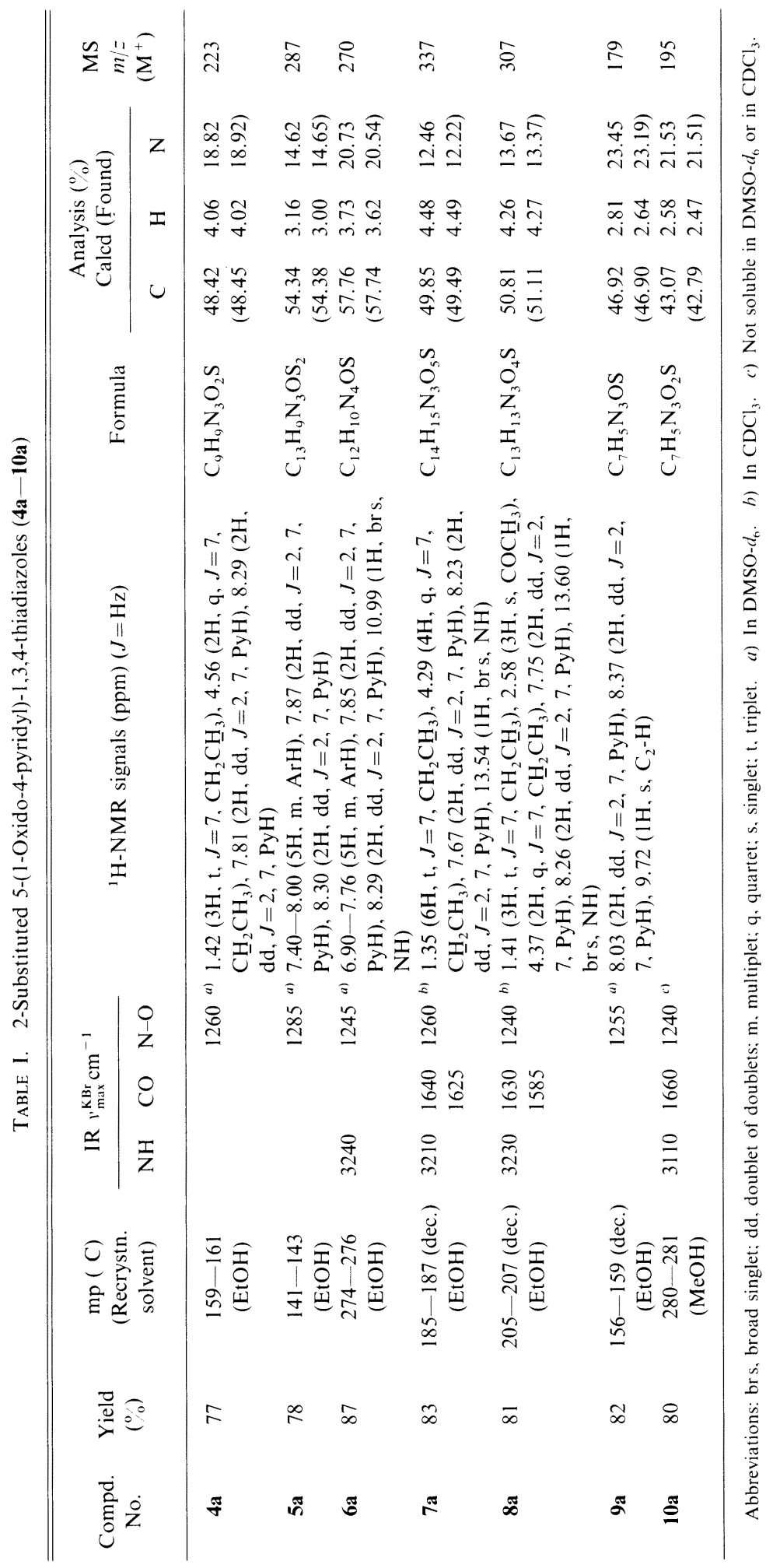




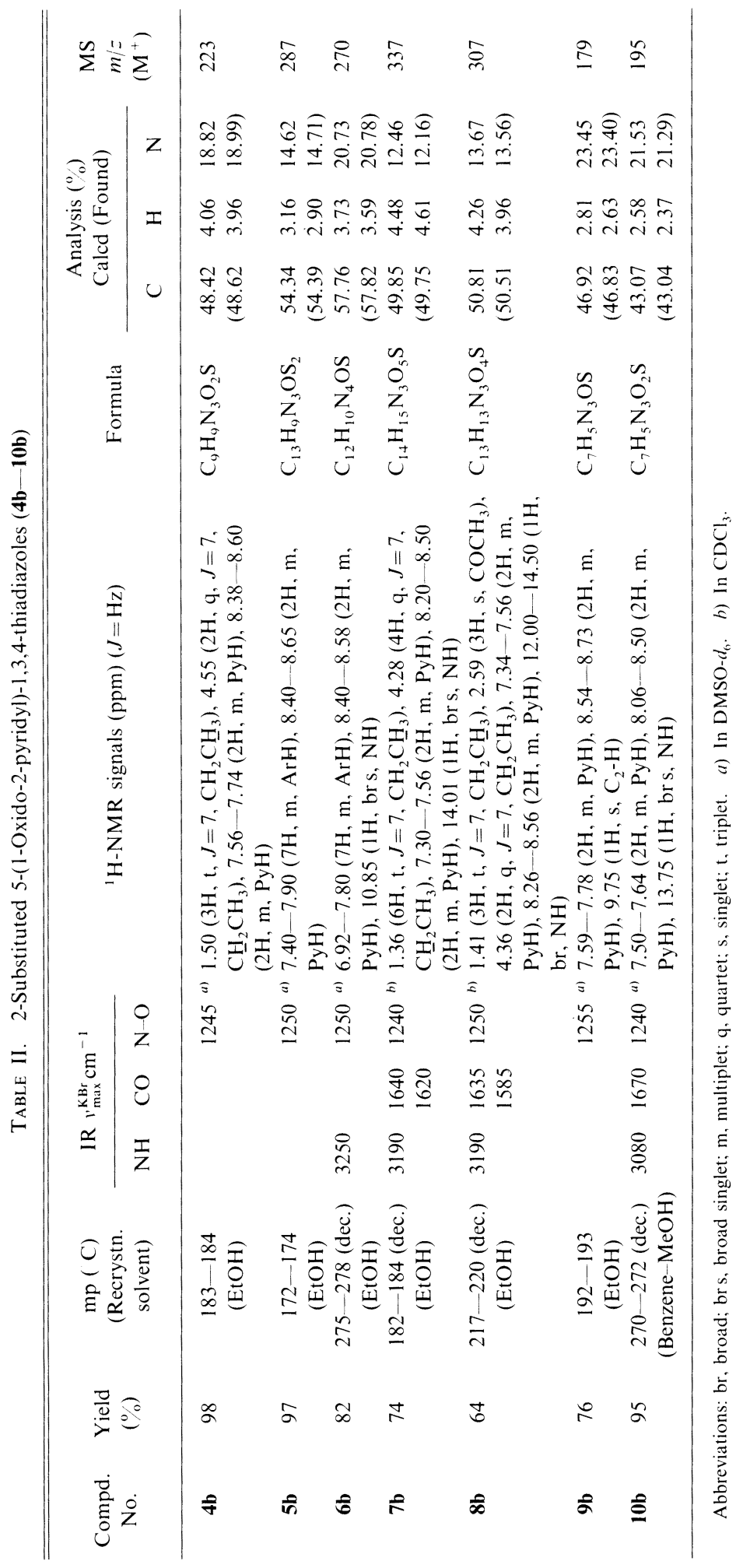




\section{Experimental}

Melting points were determined by the capillary method and are uncorrected. IR spectra were recorded on a Hitachi 215 spectrometer. ${ }^{1} \mathrm{H}-\mathrm{NMR}$ spectra were recorded on a JEOL PS-100 spectrometer using tetramethylsilane as an internal standard. Mass spectra (MS) were measured with a JEOL D-300 instrument. For column chromatography, Silica gel 60 (230 - 400 mesh, Nakarai Chemicals, Ltd.) was employed. Yields, melting points, analytical and spectral data for $\mathbf{4 a - 1 0 a}$ and $\mathbf{4 b}-\mathbf{1 0 b}$ are given in Tables I and II, respectively.

2-Ethoxy-5-(1-oxido-4-pyridyl)- (4a) and 2-Ethoxy-5-(1-oxido-2-pyridyl)-1,3,4-thiadiazole (4b)-General Procedure: A suspension of $\mathbf{3 a}$ or $\mathbf{3 b}(150 \mathrm{mg}, 0.58 \mathrm{mmol})$ in EtOH $(5 \mathrm{ml})$ was added dropwise to a stirred solution of EtONa $(1.74 \mathrm{mmol})$ in $\mathrm{EtOH}(4 \mathrm{ml})$ at room temperature. After $1 \mathrm{~h}$, the mixture was neutralized with $\mathrm{HCl} / \mathrm{EtOH}$ solution and concentrated under reduced pressure. The residue was chromatographed on a silica gel column $\left(\mathrm{CHCl}_{3}-\right.$ $\mathrm{MeOH}, 20: 1, \mathrm{v} / \mathrm{v})$. Evaporation of the eluates gave a solid, which was crystallized from EtOH to give $\mathbf{4 a}$ or $\mathbf{4 b}$.

2-Phenylthio-5-(1-oxido-4-pyridyl)- (5a) and 5-(1-Oxido-2-pyridyl)-1,3,4-thiadiazole (5b)_-General Procedure: A suspension of sodium hydride $(105 \mathrm{mg}, 2.62 \mathrm{mmol}, 60 \%$ dispersion in oil, washed twice with ether) in dry tetrahydrofuran (THF $4 \mathrm{ml}$ ) was added dropwise to a stirred solution of thiophenol $(285 \mathrm{mg}, 2.59 \mathrm{mmol})$ in dry THF $(4 \mathrm{ml})$ at room temperature. After $1 \mathrm{~h}$, a suspension of $\mathbf{3 a}$ or $\mathbf{3 b}(300 \mathrm{mg}, 1.17 \mathrm{mmol})$ in dry THF $(7 \mathrm{ml})$ was added dropwise to the solution of the sodium salt of thiophenol at room temperature. After being stirred for $15 \mathrm{~min}$, the mixture was neutralized with aqueous acetic acid, and concentrated under reduced pressure. The residue was chromatographed on a silica gel column $\left(\mathrm{CHCl}_{3}\right.$-acetone, $\left.20: 1, \mathrm{v} / \mathrm{v}\right)$. Evaporation of the eluates gave a solid, which was crystallized from $\mathrm{EtOH}$ to give $\mathbf{5 a}$ or $\mathbf{5 b}$.

2-Anilino-5-(1-oxido-4-pyridyl)- (6a) and 2-Anilino-5-(1-oxido-2-pyridyl)-1,3,4-thiadiazole (6b) —-General Procedure: A mixture of $\mathbf{3 a}$ or $\mathbf{3 b}(150 \mathrm{mg}, 0.58 \mathrm{mmol})$ and aniline $(1 \mathrm{ml})$ was stirred at $110-130 \mathrm{C}$ for $5 \mathrm{~h}$. The mixture was chromatographed on a silica gel column $\left(\mathrm{CHCl}_{3}-\mathrm{MeOH}, 20: 1, \mathrm{v} / \mathrm{v}\right)$. Evaporation of the eluates gave a solid, which was crystallized from EtOH to give $\mathbf{6 a}$ or $\mathbf{6 b}$.

Diethyl 5-(1-Oxido-4-pyridyl)- (7a) and Diethyl 5-(1-Oxido-2-pyridyl)-2,3-dihydro-1,3,4-thiadiazol-2-ylidenemalonate (7b) General Procedure: A suspension of sodium hydride $(117 \mathrm{mg}, 2.93 \mathrm{mmol}, 60 \%$ dispersion in oil, washed twice with ether) in dry THF $(4 \mathrm{ml})$ was added dropwise to a stirred solution of diethyl malonate $(470 \mathrm{mg}$, $2.93 \mathrm{mmol})$ in dry THF $(4 \mathrm{ml})$ at room temperature. After $1 \mathrm{~h}$, a suspension of $\mathbf{3 a}$ or $\mathbf{3 b}(150 \mathrm{mg}, 0.58 \mathrm{mmol})$ in dry THF $(7 \mathrm{ml})$ was added dropwise to the solution of the sodium salt of diethyl malonate at room temperature. After being stirred for $3 \mathrm{~h}$, the mixture was neutralized with aqueous acetic acid, and concentrated under reduced pressure. The residue was chromatographed on a silica gel column $\left(\mathrm{CHCl}_{3}-\mathrm{MeOH}, 20: 1, \mathrm{v} / \mathrm{v}\right)$. Evaporation of the eluates gave a solid, which was crystallized from EtOH to give $7 \mathbf{a}$ or $\mathbf{7 b}$.

Ethyl 1-(5-(1-Oxido-4-pyridyl)- (8a) and Ethyl 1-(5-(1-Oxido-2-pyridyl)-2,3-dihydro-1,3,4-thiadiazol-2-ylidene)-1acetylacetate (8b) General Procedure: A suspension of sodium hydride (117 mg, $2.93 \mathrm{mmol}, 60^{\circ}{ }^{\circ}$ dispersion in oil. washed twice with ether) in dry THF $(4 \mathrm{ml})$ was added dropwise to a stirred solution of ethyl acetoacetate $(380 \mathrm{mg}$, $2.92 \mathrm{mmol})$ in dry THF $(4 \mathrm{ml})$ at room temperature. After $1 \mathrm{~h}$, a suspension of $\mathbf{3 a}$ or $\mathbf{3 b}(150 \mathrm{mg}, 0.58 \mathrm{mmol})$ in dry THF $(7 \mathrm{ml})$ was added dropwise to the solution of the sodium salt of ethyl acetoacetate at room temperature. After being stirred at $70^{\circ} \mathrm{C}$ for $1 \mathrm{~h}$, the mixture was neutralized with aqueous acetic acid, and concentrated under reduced pressure. The residue was chromatographed on a silica gel column $\left(\mathrm{CHCl}_{3}-\mathrm{MeOH}, 20: 1, \mathrm{v} / \mathrm{v}\right)$. Evaporation of the eluates gave a solid, which was crystallized from EtOH to give $\mathbf{8 a}$ or $\mathbf{8 b}$.

2-(1-Oxido-4-pyridyl)- (9a) and 2-(1-Oxido-2-pyridyl)-1,3,4-thiadiazole (9b)—General Procedure: $\mathrm{NaBH}_{4}$ (for $\mathbf{3 a}, 56 \mathrm{mg}, 1.48 \mathrm{mmol}$; for $\mathbf{3 b}, 90 \mathrm{mg}, 2.38 \mathrm{mmol})$ was added portionwise to a stirred suspension of $\mathbf{3 a}$ or $\mathbf{3 b}(150 \mathrm{mg}$, $0.58 \mathrm{mmol})$ in $\mathrm{EtOH}(4 \mathrm{ml})$ at $0 \mathrm{C}$. After being stirred at room temperature for $1 \mathrm{~h}$, the mixture was neutralized with acetic acid, and concentrated under reduced pressure. The residue was chromatographed on a silica gel column $\left(\mathrm{CHCl}_{3}-\mathrm{MeOH}, 20: 1, \mathrm{v} / \mathrm{v}\right)$. Evaporation of the eluates gave a solid, which was crystallized from EtOH to give 9a or 9 b.

5-(1-Oxido-4-pyridyl)- (10a) and 5-(1-Oxido-2-pyridyl)-2,3-dihydro-1,3,4-thiadiazol-2-one (10b) -General Procedure: A mixture of $\mathbf{3 a}$ or $3 \mathbf{b}(150 \mathrm{mg}, 0.58 \mathrm{mmol})$ and $2 \mathrm{~N} \mathrm{HCl}(7 \mathrm{ml})$ was refluxed for $3 \mathrm{~h}$. The mixture was neutralized with saturated $\mathrm{K}_{2} \mathrm{CO}_{3}$ aqueous solution. i) For 3a: The resulting solid was collected by filtration and washed with hot $\mathrm{MeOH}$ to give 10a. ii) For $\mathbf{3 b}$ : The mixture was concentrated under reduced pressure. The residue was chromatographed on a silica gel column $\left(\mathrm{CHCl}_{3}-\mathrm{MeOH}, 20: 1, \mathrm{v} / \mathrm{v}\right)$. Evaporation of the eluates gave a solid, which was crystallized from benzene- $\mathrm{MeOH}$ to give $\mathbf{1 0 b}$.

2-(4-Pyridyl)-1,3,4-thiadiazole (11c)-A mixture of 9 a (100 mg, $0.56 \mathrm{mmol})$ and $\mathrm{Na}_{2} \mathrm{~S}_{2} \mathrm{O}_{4}(780 \mathrm{mg}, 4.48 \mathrm{mmol})$ in $50 \%$ aqueous EtOH $(8 \mathrm{ml})$ was refluxed for $15 \mathrm{~min}$. The mixture was extracted with $\mathrm{CHCl}_{3}(3 \times 50 \mathrm{ml})$. The combined extract was washed with brine, and dried over $\mathrm{Na}_{2} \mathrm{SO}_{4}$. After removal of the solvent by evaporation, the residue was crystallized from ether to give $11 \mathrm{c}\left(86 \mathrm{mg}, 94^{\circ}\right)$ as colorless crystals, $\mathrm{mp} 112-114^{\circ} \mathrm{C}$. IR $(\mathrm{KBr})$ : $1600 \mathrm{~cm}^{-1} .{ }^{1} \mathrm{H}-\mathrm{NMR}\left(\mathrm{DMSO}-d_{6}\right) \delta: 7.98(2 \mathrm{H}, \mathrm{dd}, \mathrm{ArH}), 8.80(2 \mathrm{H}, \mathrm{dd}, \mathrm{ArH}), 9.82\left(1 \mathrm{H}, \mathrm{s}, \mathrm{C}_{2}-\mathrm{H}\right)$. Anal. Calcd for $\mathrm{C}_{7} \mathrm{H}_{5} \mathrm{~N}_{3} \mathrm{~S}: \mathrm{C}, 51.52 ; \mathrm{H}, 3.09 ; \mathrm{N}, 25.75$. Found: C, 51.57; H, 2.96; N, 25.72.

2-(2-Pyridyl)-1,3,4-thiadiazole (11d)—A mixture of $9 b$ ( $100 \mathrm{mg}, 0.56 \mathrm{mmol})$ and $\mathrm{Na}_{2} \mathrm{~S}_{2} \mathrm{O}_{4}(2.918 \mathrm{~g}, 16.76 \mathrm{mmol})$ in $50 \%$ aqueous EtOH $(15 \mathrm{ml})$ was refluxed for $1 \mathrm{~h}$. The mixture was extracted with $\mathrm{CHCl}_{3}(3 \times 80 \mathrm{ml})$. The combined 
extract was washed with brine, and dried over $\mathrm{Na}_{2} \mathrm{SO}_{4}$. After removal of the solvent by evaporation, the residue was chromatographed on a silica gel column $\left(\mathrm{CHCl}_{3}-\mathrm{MeOH}, 50: 1, \mathrm{v} / \mathrm{v}\right)$. Evaporation of the eluates gave a solid, which was crystallized from petroleum ether to give $11 \mathrm{~d}\left(51 \mathrm{mg}, 56 \%\right.$ ), mp $80-82^{\circ} \mathrm{C}$ (lit. ${ }^{8)} 83-84{ }^{\circ} \mathrm{C}$ ).

Acknowledgement The authors wish to thank Mrs. M. Ohe for elemental analyses, and Mrs. Y. Yoshioka for MS. This work was supported in part by a grant from the Ministry of Education, Science and Culture, Japan.

\section{References}

1) G. Korins, "Comprehensive Heterocyclic Chemistry," Vol. 6, ed. by Kevine T. Potts, Pergamon Press Ltd., 1984, pp. $545-577$.

2) A. Alemagna, T. Bacchetti, and P. Beltrame, Tetrahedron, 24, 3209 (1968); T. Saito, N. Saheki, M. Hatanaka, and T. Ishimaru, J. Heterocycl. Chem., 20, 73 (1983).

3) H. Newman, E. L. Evans, and B. Angier, Tetrahedron Lett., 1968, 5829.

4) E. Hayashi and Y. Tamura, Yakugaku Zasshi, 90, 594 (1970); E. Hayashi, T. Higashino, E. Oishi, and M. Sano, ibid., 87, 687 (1967); E. Hayashi and T. Watanabe, ibid., 88, 94 (1968); A. Yamane, A. Matsuda, and T. Ueda, Chem. Pharm. Bull., 28, 150 (1980); A. Matsuda, Y. Nomoto, and T. Ueda, ibid., 27, 183 (1979).

5) K. Fujii, H. Yoshikawa, and M. Yuasa, Yakugaku Zasshi, 74, 1056 (1954).

6) S. Kubota, K. Toyooka, H. K. Misra, M. Kawano, and M. Shibuya, J. Chem. Soc., Perkin Trans. I, $1983,2957$.

7) B. DeCroix, M. J. Strauss, A. DeFusco, and D. C. Palmer, J. Org. Chem., 44, 1700 (1979).

8) P. Hemmerich, B. Prijs, and H. Erlenmeyer, Helv. Chim. Acta, 41, 2058 (1958). 